$\mathbb{T}$ periodica polytechnica

\author{
Social and Management Sciences \\ $19 / 2$ (2011) 6366 \\ doi: 10.3311/pp.so.2011-2.02 \\ web: http://www.pp.bme.hu/so \\ (c) Periodica Polytechnica 2011
}

RESEARCH ARTICLE

\section{Contextual images as visual metaphors}

\author{
Kövecses Zoltán
}

Received 2011-06-07

\section{Abstract \\ In the standard version of conceptual metaphor theory,} metaphors are stable connected structures in the conceptual system that emerge either because there is some similarity between two domains of experience (resemblance-based metaphors) or because the two domains are correlated in bodily experience (correlation-based metaphors). I propose that in addition to these two types of metaphor there is a third one, I call them "context-induced" metaphors. These metaphors emerge from the (immediate and less immediate) context in which conceptualizers conceive of ideas in metaphorical ways.

I suggest that the context can have a priming effect on (metaphorical) conceptualization. The effect of various kinds of context on metaphorical conceptualization can take a variety of forms, and several of them produce imagistic metaphors. The kinds of contexts that can produce context-induced metaphors include the following: (1) the immediate physical setting, (2) what we know about the major entities participating in the discourse, (3) the immediate cultural context, (4) the immediate social setting, and (5) the immediate linguistic context itself.

Of these, the context that most clearly produces visual metaphors is the immediate physical setting. Various aspects of the physical setting can prompt conceptualizers to select various (visual, auditory, etc.) images from the context as source domains for their metaphorical targets. This process can be either conscious or unconscious. In the paper, I discuss several examples of imagistic metaphors of the visual kind.

\section{Keywords}

context $\cdot$ image $\cdot$ metaphor $\cdot$ imagistic metaphor

\section{Kövecses Zoltán}

Department of American Studies, Eötvös Loránd University, 1088 Budapest, Rákóczi út 5, Hungary

e-mail: kovecses.zoltan@btk.elte.hu

\section{Images and image schemas}

What kind of form does thought (that is, the combination of concepts) have in an experientialist conceptual system? Most cognitive linguists propose that thought is not based on propositions, which are strings of arbitrary symbols, similar to the arbitrary character of the linguistic sign. Instead, thought involves the use of highly abstract but experientially-based image schemas [3-5, 9, 11] . These are schematizations of some of our most basic experiences that have to do with motion, space, vision, force, and so forth. In thought, they are combined to yield complex structures for the conceptualization of the world, and in metaphorical thought they are metaphorically projected onto abstract domains of experience. By virtue of the fact that they derive from basic human experience, image schemas bear an analogical, rather than an arbitrary, relationship to what they are used to conceptualize. In other words, the conceptualization of the world in the experientialist model of the conceptual system is imagistic, rather than propositional.

By definition, concepts in a perceptual, modal, or experientialist, conceptual system must be embodied. In the cognitive linguistic view, the embodiment of concepts arises in several ways. First, concepts are based on image schemas that constitute early preconceptual experiences and they are constantly reinforced in everyday life [5,9]. Such image schemas as container, part-whole, source-path-goal, force and resistance to force, and others underlie many of our concepts. For example, the container image schema defines more specific concepts such as in, out, and enter, the source-path-goal schema defines concepts such as journey, arrive, travel, and leave, and the force schema defines concepts such as push, pull, resist, and emotion. Second, in many cases concepts are defined by properties that are "interactional," and not objectively inherent in entities (see, e.g. [10, 12]). Such properties include sensory-motor activities, perceptual shape and other qualities, relative size, function, goal, and several additional ones. These are properties that emerge from our interactions with objects.

Images are much less schematic than image schemas, in that they contain rich details of what we perceive of the world in the course of our interaction with it. The images we perceive in the 
various modalities of perception (visual, tactile, auditory, etc.) are specific and fully-felt experiences in context. It is commonplace knowledge that of these images visual ones predominate.

As we build concepts for our experiences that contain such visual images, visual imagery becomes a part of many of our best known metaphorical source domains. The concepts of building (as in theories are buildings), fire (as in love is fire), war (as in argument is war), machine (as in the mind is a machine), and many others, all contain visual images. However, the present paper does not deal with such visual images present in highly conventional conceptual metaphors; instead, it attempts to account for the role visual images play in the creation of largely novel metaphors in what I call "immediate physical contexts."

For the purposes of the present paper, I also distinguish the visual metaphors that arise from the immediate physical context from the visual (commonly called "pictorial") metaphors that can be found in cartoons, films, advertisements, pictures, and so on. This latter category of visual metaphors is studied intensively by Charles Forceville (see, e.g., Forceville, 2006, 2008), together with multimodal metaphors.

\section{Visual images and local contexts}

Metaphorical conceptualization is affected not only by the global context (such as the general physical, social, cultural, etc. environment) but also by more immediate local contexts (see [7, 8] ). These include the immediate physical setting, the knowledge about main entities in the discourse, the immediate cultural context, the immediate social setting, and the immediate linguistic context. Local and global contexts are assumed here to form a continuum from the most immediate local contexts to the most general global ones. I will first describe an example of how the immediate physical context can affect the selection of metaphors in an everyday situation, then I will analyze a more complex case in the use of metaphor in psychological counseling, and finally I turn to an example from the use of metaphor in poetry. In all of these cases, my goal will be to examine how visual images can, and do, result in metaphors that range from less novel to highly novel ones.

\section{An everyday example}

The immediate physical setting can influence the selection and use of particular metaphors in discourse. The physical setting comprises, among possibly other things, the physical events and their consequences that make up or are part of the setting, the various aspects of the physical environment, and the perceptual qualities that characterize the setting. I will briefly discuss an example for the first. We can find examples for the latter two in other studies (e.g. [1 1,13$]$ ), though their analyses are not formulated in terms of the present framework.

Physical events and their consequences are well demonstrated by a statement made by the American journalist who traveled to New Orleans to do an interview with Fats Domino two years after the devastation wreaked by hurricane Katrina, when the city of New Orleans was still struggling with many of the consequences of the hurricane. The journalist comments:

'The 2005 hurricane capsized Domino's life, though he's loath to confess any inconvenience or misery outside of missing his social circle ..." (USA TODAY, 2007, September 21, Section 6B).

The metaphorical statement "The 2005 hurricane capsized Domino's life" is based on the general metaphor life is a journey and its more specific version life is a sea journey. The sea journey source domain is chosen probably because of the role of the sea in the hurricane. More importantly, it should be noted that the verb capsize is used (as opposed to, say, run aground), though it is not a conventional linguistic manifestation of either the general journey or the more specific sea journey source domains. I suggest that this verb is selected by the journalist as a result of the then (still) visible consequences in New Orleans of the hurricane as a devastating physical event. The physical setting thus possibly triggers the extension of an existing conventional conceptual metaphor and causes the speaker/conceptualizer to choose a metaphorical expression that best fits that setting. We can think of this "triggering effect" as a form of priming that comes from the immediate local context.

\section{An example from counseling}

The main entities participating in discourse include the speaker (conceptualizer), the hearer (addressee/conceptualizer), and the entity or process we talk about (topic). We can find cases where the selection of a metaphor depends on knowledge about the conceptualizer (speaker or hearer). To demonstrate this, I take an example from my previous work [6] but reanalyze it here. What is especially intriguing about such cases is that the speaker/author's (conceptualizer's) knowledge about him- or herself does not need to be conscious. As one would expect, one important source of such cases is the area of therapy or psychological counseling. In a therapeutic context people commonly create novel metaphors as a result of unique and traumatic life experiences. The metaphors that are created under these circumstances need not be consciously formed. The example comes from an article in the magazine $A \mathcal{E} U$ (March, 2003) about photographic artist Frank Jump.

Frank Jump photographs old painted mural advertisements in New York City. He has AIDS, but he has outlived his expected life span. His life and his art are intimately connected metaphorically. The conceptual metaphor operative here could be put as follows: surviving aids despite predictions to the contrary is for the old mural advertisements to survive their expected "life span." At first, Jump was not consciously aware that he works within the frame of a conceptual metaphor that is based on his condition. In his own words:

In the beginning, I didn't make the connection between the 
subject matter and my own sero-positivity. I was asked to be part of the Day Without Art exhibition a few years ago and didn't think I was worthy-other artists' work was much more HIVspecific. ... But my mentor said, "Don't you see the connection? You're documenting something that was never intended to live this long. You never intended to live this long." [p. 27; italics in the original]

The mentor made the conceptual metaphor conscious for the artist. I believe something similar is happening in many cases of psychotherapy and counseling. It could be argued that it is the mentor who conceptualizes the situation for the artist. This may be a possible interpretation, but, on the other hand, when Jump says "In the beginning, I did not make the connection between the subject matter and my own sero-positivity", it is clear that the connection is in his unconscious and readily available to him as well.

Obviously, the metaphor surviving aids despite predictions to the contrary is for the old mural advertisements to survive their expected "life span" is anything but a conventional conceptual metaphor. The metaphor is created by Frank Jump as a novel analogy - the unconscious but nevertheless real analogy between surviving one's expected life span as a person who has AIDS and the survival of the mural advertisements that were created to be visible on the walls of buildings in New York City for only a limited amount of time. In this case, (unconscious) self-knowledge leads the conceptualizer to find the appropriate analogy. The analogy is appropriate because the source and the target domains share schematic structural resemblance; namely, an entity existing longer than expected. The resulting metaphor(ical analogy) is novel and creative and it comes about as a result of what the conceptualizer knows about himself.

But we can ask how the creation of the metaphor actually takes place. We can assume that as Jump wanders around the city looking for mural advertisements and notices one, a frame for such advertisements is activated in his head. The frame contains the various properties of mural advertisements. There is also a huge amount of background knowledge associated with the frame. What gets highlighted, or profiled, from all of this knowledge is the intended future, the destiny of the advertisements. This gets selected because the frame for mural advertisements shares with the target domain (Jump's life) some genericlevel information: an entity existing longer than expected. In other words, the physical context (mural advertisements on the walls of old New York City buildings) furnishes a potential target domain with an appropriate source domain. This is another way in which the physical context can prime the selection of a particular source domain that fits a particular target.

\section{A poetic example}

Context can be used in poetry in two ways:

Poets may describe the context in which they create poetry. (literal use)
They may use context as a means of talking about something else. (figurative use)

When the first is the case, we get straightforward examples of describing a scene, such as in Matthew Arnold's Dover Beach:

"The sea is calm to-night.

The tide is full, the moon lies fair Upon the straits,- on the French coast, the light

Gleams and is gone; the cliffs of England stand,

Glimmering and vast, out in the tranquil bay.

Come to the window, sweet is the night-air!"

(retrieved from http://www.artofeurope.com/arnold/arn1.htm) [14].

This is a largely literal description of the physical context, more precisely, what the author can see around him. But my concern will be with the second use of context, or scene.

Let us now continue with the Arnold poem:

"The sea of Faith

Was once, too, at the full, and round earth's shore

Lay like the folds of a bright girdle furled.

But now I only hear

Its melancholy, long, withdrawing roar,

Retreating, to the breath

Of the night-wind, down the vast edges drear

And naked shingles of the world."

At work in this stanza are two conceptual metaphors: health is wholeness and perfection/completeness is roundness, as indicated by the expressions "at the full" (wholeness) and "and round earth's shore" (roundness). The stanza, we understand, is about the health and perfection of the human condition until the coming of the changes that were happening at the time of writing the poem: the changes to the established order of the world in which religion played a major role. These two extremely general metaphors can be instantiated (and could be instantiated by Arnold) in many different ways; the wholeness and roundness of a diverse set of other things could be utilized. The question arises why they are made conceptually-linguistically manifest in the particular way they are; that is, by the metaphor "the sea of Faith" in the first line of the stanza. This metaphor assumes the conceptual metaphors (Christian) faith is the sea and people are the land. The sea was once full and covered the land all around, and in the same way Christian faith provided people with a spiritual health (health is wholeness) and a perfect state of the human condition (perfection is roundness), unlike the situation in which Arnold wrote the poem. In addition, the full cover of faith protected people from the dangers of the new times that now threaten a faithless world. These ideas were given expression in these particular ways, we can safely assume, because of what Arnold saw before him at the time of creating the poem: the ebb and flow of the sea. As the sea retreats, that is, as faith disappears, the world becomes a less healthy and less perfect place, unprotected by faith. 
This is a more complex situation than the previous ones. The reason is that (1) the author has a particular idea (the human condition was good/perfect when there was faith, and faith protected people; but now dangers threaten a faithless world, and the human condition is not good/perfect); (2) crucial aspects of the idea are conceptualized conventionally: health is wholeness and perfection is roundness; (3) the conventional metaphors constituting crucial aspects of the idea need to be expressed in specific ways because the conventional metaphors are generic-level ones that do not entail the dangers with which the new situation threatens; (4) in order to recognize the danger of the situation for human beings, there must be a clear indication that it is human beings who are threatened by the lack of faith. This is accomplished by the two relatively novel conceptual metaphors: (Christian) faith is the sea and, especially, people are the land; (5) finally, the resulting two metaphors are allowed to interact with each other within the framework and confines of the previously mentioned metaphors (health is wholeness and perfection is roundness). This means that the "wholeness" and "roundness" of the sea around the earth indicates the healthiness and perfection of the human condition, whereas their lack indicates danger.

\section{Conclusions}

In the paper, I raised the issue of the role of visual images in metaphorical conceptualization. I noted that, in addition to visual aspects of many metaphorical source domains, there are visual images in the online physical context of metaphorical conceptualization that can serve as source domains of novel metaphors. I suggested that we can think of such cases as the visual images priming the selection of metaphorical source domains.

I argued, furthermore, that the visual metaphors created this way work on several levels of complexity. In the everyday example, the visual image (capsized boats in the sea) simply triggered the use of a conventional source domain (sea journey) that is compatible with that visual image. In the example related to counseling, a visual image prompts the selection of a source domain based on highly skeletal structural similarity between the source and the target (but see also [2] ). Finally, in the example of poetic metaphor, a number of conventional and unconventional metaphors interact with each other and the ideas to be expressed by the speaker/conceptualizer. This example presents a cognitively complex situation, and it indicates that visual images are involved in the creation of metaphors in a variety of ways, ranging from simply priming source domains to priming a complex set of conceptual interactions that yield a complex source domain.

\section{References}

1 Boers F, When a bodily source domain becomes prominent, Metaphor in Cognitive Linguistics (Gibbs R, Steen G, eds.), John Benjamins, Amsterdam, 1999, 47-56.
2 Urena $\mathbf{J} \mathbf{M}$, Faber $\mathbf{P}$, Reviewing imagery in resemblance and nonresemblance metaphors, Cognitive Linguistics, 21(1), (2010), 123-149, DOI 10.1515/COGL.2010.004.

3 Gibbs R, Embodiment and Cognitive Science, Cambridge University Press, New York, 2006.

4 Hampe B (ed.), From Perception to Meaning: Image Schemas in Cognitive Linguistics, Mouton de Gruyter, Berlin, 2005.

5 Johnson M, The Body in the Mind, The University of Chicago Press, Chicago, 1987.

6 Kövecses Z, Metaphor in Culture, Universality and Variation, Cambridge University Press, Cambridge, 2005.

7 , Metaphor. A Practical Introduction., Oxford University Press, New York, 2010. Second Edition.

8 , A new look at metaphorical creativity in cognitive linguistics, Cognitive Linguistics, 21(4), (2010), 663-697, DOI 10.1515/COGL.2010.021.

9 Lakoff G, Women, Fire, and Dangerous Things, The University of Chicago Press, Chicago, 1987.

10 Lakoff G, Johnson M, Metaphors We Live By, The University of Chicago Press, Chicago, 1980.

11 Langacker R, Foundations of Cognitive Grammar, Stanford University Press, Stanford, 1987.

12 Rosch E, Cognitive reference points, Cognitive Psychology, 7, (1975), DOI 10.1016/0010-0285(75)90021-3.

13 Semino E, Metaphor in Discourse, Cambridge University Press, Cambridge, 2008.

14 Matthew A, Dover Beach, available at http://www.artofeurope.com/ arnold/arn1.htm 